\title{
Author Information Section
}

\author{
Journal of Pediatric Rehabilitation Medicine \\ Financial Disclosure \& Authorship Agreement
}

Name:

Address:

E-Mail:

Phone Number:

Manuscript Name and/or Number:

Corresponding Author:

Financial Disclosure Policy (applicable for the last two years)

1. I I certify that I have no financial conflict of interest relevant to the publication of the subject matter or materials in this manuscript.

2. I certify that all my financial conflicts* of interest are disclosed in the Acknowledgment section of the manuscript.

* A conflict of interest is defined as any financial remuneration received within the last two years greater than $\$ 500$ in employment/affiliation, grants or funding(Non profit or government), consulting, honorarium, speakers bureaus, stocks, expert testimony, royalties or patents.

Please provide the above in the acknowledgment section at the end of the manuscript

Signature

Date

Authorship Responsibility

I certify that

1. I accept responsibility for this manuscript and that it represents original and valid work and this it is not being considered for publication elsewhere.

2. That I will provide the original data if requested for review and statistical analysis.

3. That as corresponding author, that myself and all authors meet the International Committee of Medical Journal Editors(www.http.icmje) definition of authorship.

Signature

Date

Please fax back to Lila J. Lee-Tramiel@ 510-450-5821 or email scanned copy to: 1tramiel@mail.cho.org 


\section{Statement of Informed Consent and Human/Animal Rights}

All studies involving human and/or animals must include the statement that the Institutioanl Review Board(IRB) and/or Animal Care Board and/or Ethics Committee Approval has been obtained. Informed consent must be obtained for all human subjects and appropriately described in the manuscript. Authors must provide an electonic copy of the appropriate approval to the editorial office prior to publication.

Note: Authors must keep on file a release for any photographs submitted and or used with identifying information. The 1996 Health Insurance Portability and Accountability Act (HIPAA) for manuscripts from United States institutions must be followed.

\section{Statement of Conflict of Interest}

A conflict of interest is defined as any financial remuneration received within the last two years greater than $\$ 500$ in employment/affiliation, grants or funding(Non profit or government), consulting, honorarium, speakers bureaus, stocks, expert testimony, royalties or patents. All authors are required to disclose these in the acknowledgement section and to provide a signed copy of the disclosure form to the editorial office.

\section{Statement of Authorship}

The journal adheres to the International Committee of Medical Journal Editors(ICJME) (http://www.icmje. org) definition of authorship. All corresponding authors are required to provide a signed copy of the authorship declaration form to the editorial office.

\section{Statement of Funding}

All manuscripts must provide the funding source and grant number for the study in the acknowledgement section. NIH/federally funded studies are to be submitted to Pubmedcentral (http://www.nihms.nih.gov/db/sub.cgi) by the corresponding author within 12 months.

\section{Clinical Trial Registration}

The journal adheres to the ICJME policy for registration of all trials in a public trials registry that is acceptable to the ICMJE (http://www.icmje.org/faq_clinical. html). In June 2007 the ICMJE adopted the World Health Organization's definition of a clinical trial as: "any research study that prospectively assigns human participants or groups of humans to one or more health-related interventions to evaluate the effects on health outcomes".

Above statements supercede all previous policies and are effective immediately. 


\section{Vancouver Reference style example for the journal}

\section{References}

1. Place citations as numbers in square brackets in the text. All publications cited in the text should be presented in a list of references following the text of the manuscript. Only articles published or accepted for publication should be listed in the reference list. Submitted articles can be listed in the text as (author(s), unpublished data).

2. All authors should be listed in the reference list.

3. References should be listed in the order of appearance in the following style:

\section{References}

[1] Alzheimer Research Forum, Drugs in Clinical Trials: AAB-001, http://www.alzforum.org/drg/drc/detail.asp?id=101, Last updated May 29, 2007, Accessed on January 29, 2008.

[2] M.A. Smith, Oxidative stress and iron imbalance in Alzheimer disease: how rust became the fuss! In Alzheimer's Disease: A Century of Scientific and Clinical Research, G. Perry, J. Avila, J. Kinoshita, M.A. Smith eds, IOS Press, Amsterdam, 2006, pp. 305-308.

[3] H. Hara, A. Monsonego, K. Yuasa, K. Adachi, X. Xiao, S. Takeda, K. Takahashi, H.L. Weiner and T. Tabira, Development of a safe oral Abeta vaccine using recombinant adeno-associated virus vector for Alzheimer's disease, J Alzheimers Dis 6 (2004), 483-488.

[4] G. Paxinos and C. Watson, The Rat Brain in Stereotaxic Coordinates, Academic Press, Sydney, 1986.

[5] X. Zhu, G. Perry and M.A. Smith, (2004) Two hits and you're out? A novel mechanistic hypothesis of Alzheimer disease, Alzheimer Research Forum, http://www.alzforum.org/res/ adh/cur/zhu/default.asp, Posted 23 October 2004, Accessed January 29, 2008. 